\title{
Trophic ecology of blue whiting in the Barents Sea
}

Andrey Dolgov (dolgov@pinro.ru)

Edda Johannesen (edda.johannesen@imr.no)

Erik Olsen (erik.olsen@imr.no)

Mikko Heino (mikko.heino@imr.no)

\section{Approved by}

Ulf Dieckmann

Program Leader, EEP

July 2011 


\section{Contents}

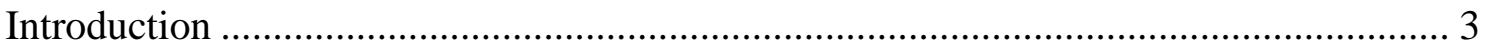

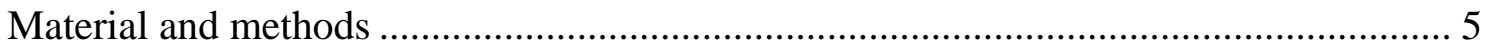

Data acquisition and diet analysis .......................................................................... 5

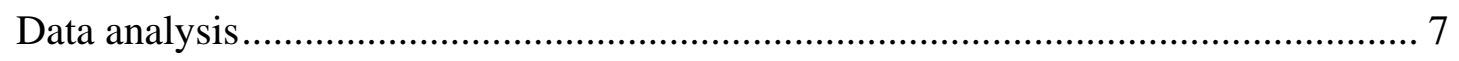

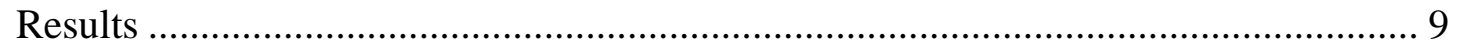

Abundance and distribution of blue whiting ............................................................ 9

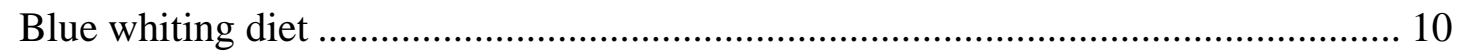

Diet and spatial overlap between blue whiting and other planktivorous fish............. 12

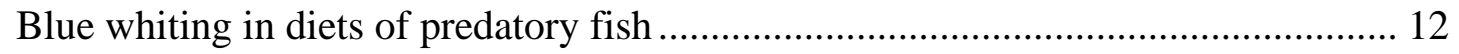

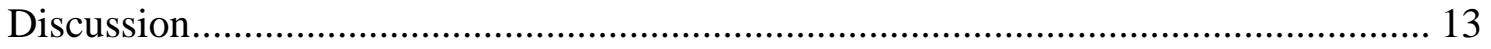

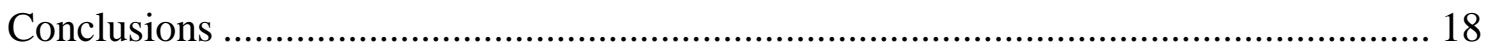

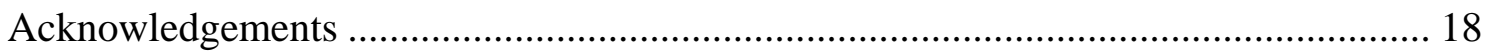

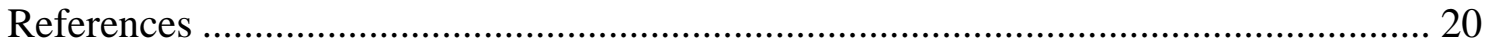


Trophic ecology of blue whiting in the Barents Sea

Andrey Dolgov, Edda Johannesen, Mikko Heino and Erik Olsen

\section{Abstract}

The distribution of blue whiting extends from the Norwegian Sea into the Barents Sea from the south-west. In recent years, both the abundance and area of distribution of blue whiting within the Barents Sea have increased dramatically. In order to evaluate the trophic impact of this increase, we analysed dietary material from blue whiting. A total of 54 prey species or higher taxa were identified. The main prey was krill. However, diet varied geographically and ontogenetically: the proportion of fish in the diet was higher in large blue whiting and in the northernmost parts of its range. Blue whiting overlaps geographically with other pelagic species at the edge of its distribution in the Barents Sea; juvenile herring in the south, polar cod in the north and capelin in the north-east. The overlap in diet between blue whiting and these other pelagic species ranged from 6 to $86 \%$, and was highest with capelin in areas where both species feed on hyperiids and krill. The importance of blue whiting as a prey for predatory fish was greatest in the areas with the highest abundance of this species, but overall, blue whiting were unimportant as a prey for piscivorous fish in the Barents Sea.

Keywords: blue whiting, competition, diet, ecosystem survey, predation, trophic interactions

Andrey Dolgov: Polar Research Institute of Marine Fisheries and Oceanography (PINRO), Knipovich-St., 6, Murmansk, 183038, Russia. Edda Johannesen and Erik Olsen: Institute of Marine Research, P.O. Box 1870 Nordnes, NO-5817 Bergen, Norway. Mikko Heino: 
Institute of Marine Research, P.O. Box 1870 Nordnes, NO-5817 Bergen, Department of Biology, University of Bergen, P.O. Box 7800, NO-5020 Bergen, Norway and Evolution and Ecology Programme, International Institute for Applied Systems Analysis, A-2361 Laxenburg, Austria. Correspondence to Andrey Dolgov: tel: +7 8152 472469; fax: +7 8152 473331; e-mail: dolgov@pinro.ru. 


\section{Introduction}

Blue whiting (Micromesistius poutassou) support one of the largest fisheries in the Atlantic, with annual catches of more than two million tonnes in 2003-2006 (ICES, 2007a). In the North-east Atlantic, blue whiting are treated as a single stock for stock assessment purposes (ICES, 2007a), but the stock is regarded as consisting of two main components: the southern component in the Bay of Biscay, and the northern component that extends northward from the Porcupine Bank west of Ireland (Zilanov, 1984; Monstad, 2004). The northern component makes long-distance migrations from the main feeding areas in the Norwegian Sea to its spawning area west of the British Isles. The Barents Sea is on the north-eastern fringe of the distribution of the northern component. Data from standardized surveys run in the Barents Sea since 1981 show a marked increase in the abundance of this species since about 2000 (Belikov et al., 2004; Heino et al., 2008). Concurrently, the distribution has extended towards the east and north within the Barents Sea. The greater abundance in the Barents Sea in recent years is probably due to expansion of the northern main oceanic component of the stock, which has its main feeding area in the Norwegian Sea (Varne and Mork, 2004; Heino et al., 2008). Heino et al. (2008) showed that the greater abundance and wider distribution of Barents Sea blue whiting is indirectly related to climate through a correlation with strong year classes of blue whiting spawned west of the British Isles and, to a lesser extent, directly related to climate through a positive correlation with inflows of Atlantic water into the Barents Sea.

Climate-mediated changes in the distribution and abundance of a certain species can influence other species in the food web through ecological interactions (e.g. Hamre, 1994). To date, the greater abundance of blue whiting has had no clear and obvious effect on the 
abundance of other Barents Sea species. However, the consumption of blue whiting by cod has increased in proportion to the increase in blue whiting abundance (ICES, 2007b). Blue whiting thus appear to have become a component of the food web as prey for cod. However, little is known about the diet of blue whiting themselves in the Barents Sea in recent years and thus which species blue whiting preys on. The average biomass of blue whiting in the Barents Sea from 2004-2006 was 1.1 million tonnes (Anon. 2005; Anon. 2006a; Anon. 2007), making it the second most abundant pelagic fish species in the Barents Sea in these years, after juvenile herring (Clupea harengus). Besides juvenile herring, polar cod (Boreogadus saida) and capelin (Mallotus villosus) are important pelagic species and potential competitors of blue whiting, but no studies have been made of diet overlap between blue whiting and these species.

The diet of blue whiting has been studied throughout the geographical range of the species (e.g. Timokhina, 1974; Bailey, 1982; Zilanov, 1984; Bergstad, 1991; Du Buit, 1995; Cabral and Murta, 2002; Monstad, 2004; Prokopchuk and Sentyabov, 2006), particularly in the Norwegian Sea, the most important feeding area for the Atlantic stock. While diet analyses and trophic interactions of blue whiting in the Norwegian Sea have been presented in several recent studies (Monstad, 2004; Skjoldal et al., 2004; Prokopchuk and Sentyabov, 2006; see also Bergstad, 1991), the only English-language publications on blue whiting diet from the Barents Sea are by Zilanov $(1968,1982)$, and are based on data from the 1960s and 1970s. However, the Barents Sea has undergone ecological changes since then. Furthermore, while the Barents and Norwegian Seas share some important species, they differ in many key characteristics (Yaragina and Dolgov, 2008) that might influence the trophic ecology of blue whiting. Therefore, diet information obtained in the Norwegian 
Sea is not necessarily applicable to the Barents Sea, and updated information on the trophic ecology of blue whiting in the Barents Sea is needed.

In this paper we study the diet and distribution of blue whiting in the Barents Sea from 1998-2006. We then examine spatial and dietary overlap between blue whiting and its potential competitors; juvenile herring, capelin and polar cod. Finally, we evaluate the importance of blue whiting as prey for cod, the most important fish predator in the Barents Sea (Bogstad et al., 2000), and for other piscivorous fish.

\section{Material and methods}

\subsection{Data acquisition and diet analysis}

Blue whiting is easily caught with demersal trawls in the Barents Sea, and most of the stomach samples ( $>95 \%)$ utilised in this study were taken from specimens taken by demersal trawls. The stomachs were collected on Russian and Norwegian routine research surveys in the Barents Sea (Table 1). Data from the first quarter were from the Joint IMRPINRO demersal winter survey (hereafter the "winter survey"), run every February-March since 1981. This survey covers most of the ice-free Barents Sea (Jakobsen et al., 1997). Data from the second quarter were from a Russian survey that targets redfish and haddock and that covers only a limited part of the Barents Sea in May-June (Anon., 2006b). Data from the third quarter were from the Joint IMR-PINRO ecosystem survey (hereafter the "ecosystem survey") that covers the whole of the Barents Sea and has been run every August-September since 2003 (e.g. Anon. 2005). Data from the fourth quarter are from the Russian demersal survey (hereafter the "Russian demersal survey") covering most of the Barents Sea in October-December (Lepesevich and Shevelev, 1997; Anon., 2006b). 
Trawl gear and towing time differed between the surveys. On the winter survey the towing time was 30 minutes and all vessels were equipped with the standard research bottom trawl, a Campelen 1800 shrimp trawl with $80 \mathrm{~mm}$ (stretched) mesh size in the front and a codend with 16-22 mm meshes. The horizontal opening was $20 \mathrm{~m}$, and the vertical opening was $4-5 \mathrm{~m}$. On the ecosystem survey the same gear was used but the towing time was 15 minutes. The standard towing time in PINRO surveys is one hour. Surveys in May-June used a standard $125 \mathrm{~mm}$ Russian research demersal trawl with a mesh size in the codend of $22 \mathrm{~mm}$. The surveys in October-December used a standard $125 \mathrm{~mm}$ Russian research demersal trawl with a mesh size in the codend of $16 \mathrm{~mm}$. The opening of the standard Russian research trawl was $24.5-25 \mathrm{~m}$ and the vertical opening was $6.5-7 \mathrm{~m}$.

On IMR surveys, blue whiting stomachs were removed from the fish and individually frozen on board. Stomach contents were later analysed in the laboratory on land after thawing. On PINRO vessels, diet composition was analysed from fresh stomachs on board ship. Stomachs where regurgitation had occurred, e.g. when the stomachs were found inside out in the throat of the fish, were rejected. The stomach contents were studied under a binocular microscope. Prey were counted and identified to the lowest taxonomic level possible. Prey groups were weighed to the nearest milligram (wet weight) and length measured whenever possible.

Analyses in which different surveys are compared may be confounded by differences in survey gear, procedures and area coverage. We believe that this is not an important problem for our analyses. In analyses of blue whiting catch rates (Heino et al., 2008), changes in mesh size and tow duration did not have significant effects. The availability of blue whiting to bottom gear may vary with season, due to seasonal differences in vertical 
distribution. However, we are not aware of any studies or confirmed observations of seasonal variations in the catchability of blue whiting.

Differences in towing time of 30-45 minutes should have a negligible effect on stomach content, since it takes two to three days for the Barents Sea cod to digest gammarids and three to five days to digest fish (Orlova and Matishov, 1993). Towing-induced regurgitation is a minor problem in gadoids, and since we removed regurgitated stomachs from our analysis, this will not affect the diet data.

\subsection{Data analysis}

We compared seasonal blue whiting distribution by mapping catch data from demersal trawl hauls from the winter survey, ecosystem survey and Russian demersal survey in 2003-2006. From these analyses we excluded the survey data from the second quarter because of poor spatial coverage. We calculated catch rates from the above-mentioned surveys (individuals per nautical miles towed) from a subarea covered by all surveys in all years. In addition, we used acoustic data from the ecosystem survey to map spatial overlap between blue whiting, polar cod, capelin and juvenile herring.

We characterised blue whiting diet using three indices. First, the Total Fullness Index (TFI, in $10^{4} \mathrm{~g} \mathrm{~cm}^{-3}$ ) was defined as:

$\mathrm{TFI}=10^{4} * \mathrm{~W}_{\mathrm{t}} / \mathrm{L}^{3}$

where $\mathrm{W}_{\mathrm{t}}$ is the total wet weight $(\mathrm{g})$ of prey in the stomach and $\mathrm{L}$ is the blue whiting length $(\mathrm{cm})$. 
Second, the Proportion of Total Weight (PW) was defined as:

$\mathrm{PW}_{\mathrm{i}}=\mathrm{W}_{\mathrm{i}} / \mathrm{W}_{\mathrm{t}}$,

where $\mathrm{w}_{\mathrm{i}}$ is the total wet weight $(\mathrm{g})$ of the prey $\mathrm{i}$ and $\mathrm{W}_{\mathrm{t}}$ is the total wet weight $(\mathrm{g})$ of all prey in the stomach.

Finally, the Frequency of Occurrence (FO) was defined as:

$\mathrm{FO}_{\mathrm{i}}=\mathrm{n}_{\mathrm{i}} / \mathrm{N}$

where $n_{i}$ is the number of stomachs containing the prey $i$ and $\mathrm{N}$ is the total number of stomachs. Logistic regression was applied when analysing FO.

Stomach samples from blue whiting were compared to samples from polar cod, juvenile herring and capelin. We compared samples taken at the same time of year and from the same main Russian fishing areas, but not necessarily from the same trawling stations. We calculated diet overlap between blue whiting and capelin, polar cod and herring using the Coefficient of Diet Similarity (CDS; Shorygin, 1952), defined as:

$\mathrm{CDS}=100 * \Sigma_{i} \min \left(\mathrm{PW}_{i, m}, \mathrm{PW}_{i, n}\right) / \Sigma_{i} \max \left(\mathrm{PW}_{i, m}, \mathrm{PW}_{i, n}\right)$

where $\mathrm{PW}_{i, m}$ and $\mathrm{PW}_{i, n}$ are the average weight percentages of prey $i$ in the diet of predator $\mathrm{m}$ and $\mathrm{n}$, respectively, in the samples being compared; here, area-specific averages were used. CDS can vary between $0 \%$ (no similarity) to $100 \%$ (full similarity). 
We analysed diet data from potential predators of blue whiting. Diet data on cod were sampled by the joint IMR-PINRO stomach sampling programme on the same Norwegian and Russian survey as described above, and also on board Russian commercial fishing vessels (see Mehl and Yaragina, 1992, for details of the sampling procedures). The data on other predatory fish were sampled on PINRO surveys as well as on board commercial fishing vessels throughout the year and analysed on board using standard quantitative methods (as described above for blue whiting stomachs). Thanks to the availability of a more comprehensive data-set for cod, we were able to test for the effects of season and cod length on FO of blue whiting in cod stomachs, using data from the winter survey and ecosystem survey (see above) in 2003-2006. We also tested for spatial overlap between small and large cod by correlating the log catch rate of blue whiting with the log catch rate of cod from bottom trawls taken in the course of the winter and ecosystem surveys.

\section{Results}

\subsection{Abundance and distribution of blue whiting}

Annual mean catch rates (individuals per nautical mile towed) for the winter survey (19842006), ecosystem survey (2003-2006) and Russian demersal survey (2003-2006) are shown in Figure 1. The catch rates are not directly comparable across surveys because of differences in gear, towing duration, and possibly also seasonal availability of blue whiting to the bottom trawl (see methods). With this caveat in mind, the data suggest that there are more blue whiting in the central Barents Sea in the third quarter of the year, compared to the first and fourth quarter. The data also show that blue whiting are most concentrated in the south-western Barents Sea during the first quarter, then spread out and reach their widest and most even distribution during the fourth quarter (Figure 2). 


\section{2 Blue whiting diet}

A total of 4165 blue whiting stomachs were analysed, of which 1591 (38\%) were empty. The diet is plotted on quarterly maps in Figure 3. The average size of the specimens analysed was $27 \mathrm{~cm}$ (range 13.7-45 cm), somewhat larger than the average size from the surveys (Figure 4). On average, stomach content made up 1.5\% of the total body weight of the fish, and average Total Fullness Index (TFI) was 0.88 (all stomachs).

A total of 54 species (or higher taxa) of prey were found in the blue whiting stomachs (Table 2). Crustaceans were found in $95 \%$ of the non-empty stomachs and made up $39 \%$ of the total stomach weight (all stomachs pooled). Euphausiids (krill) were the most important crustaceans in the stomachs, and were found in $60 \%$ of stomachs that contained food, making up $27 \%$ of total stomach content. Only a small proportion of the euphausiids found in the stomachs was classified to species; two species were identified, Thysanoessa inermis and Meganyctiphanes norvegica, with the latter, larger species being more important (Table 2). Amphipods, mostly pelagic hyperiids, were the second most important group of crustaceans and were found in $22 \%$ of the stomachs containing food, accounting for $7 \%$ of stomach content by weight. Copepods made up only $1 \%$ of stomach content weight and were found in less than $8 \%$ of the stomachs containing food. Other invertebrates accounted for less than $1 \%$ of total stomach content weight. Fish accounted for $60 \%$ of total stomach content weight, and fish prey were found in $24 \%$ of the nonempty stomachs. Gadoids were found in $9 \%$ of the stomachs containing food and made up $35 \%$ by weight. Surprisingly, polar cod, a cold-water species, was the most frequent fish prey in the stomachs. Blue whiting were found in four stomachs. 
Diet varied with location (Figure 3). In the central Barents Sea, smaller blue whiting fed mainly on zooplankton, in particular krill. Large individuals further north and east reached areas where they also preyed on abundant pelagic fish (capelin, polar cod) as well as juveniles of other species. Polar cod was mostly found in blue whiting taken west of Svalbard in the fourth quarter of the year (Figure 3). The intensity of feeding (measured as stomach fullness) also varied spatially and was the highest at the edge of the blue whiting distribution in the Barents Sea in the areas where the species fed on fish (Figure 3). In the areas with the highest concentration of blue whiting, the stomachs were less full and krill was the main prey (Figures 2 and 3).

The proportion of empty stomachs varied significantly by quarter (Table 3), being very high in the second quarter when 287 of the 456 stomachs examined were empty (63\%). The proportion of empty stomachs was lowest in the third quarter $(26 \%)$, whereas the proportion in the first and fourth quarter was intermediate (42 and 43\%, respectively). The proportion of blue whiting stomachs containing fish varied significantly by season (Table 3; Figure 4) and was highest in the third and fourth quarters (10\% and $18 \%$, respectively) and lowest in the first and second quarter (3\% and $2 \%)$.

The importance of fish prey increases with blue whiting size; there was no obvious size threshold at which prey preference switched from invertebrates to fish (Table 3; Figure 5). Blue whiting of length $24 \mathrm{~cm}$ (the average size caught in the surveys) included $42 \%$ fish and $41 \%$ krill in diet by weight, while krill were more important in terms of frequency of occurrence (FO). Blue whiting larger than $30 \mathrm{~cm}$ included more than $50 \%$ fish by weight in their diet. Stomach fullness (TFI) also increased with predator length (Table 3). TFI and FO were positively correlated $(\mathrm{r}=0.66)$; stomachs containing items of fish prey were fuller, 
so that larger blue whiting had fuller stomachs containing more fish prey (Table 3 ). There was no effect of fish length on the proportion of empty stomachs (Table 3).

\subsection{Diet and spatial overlap between blue whiting and other planktivorous fish}

Several planktivorous fish species that potentially compete with blue whiting for similar prey inhabit the Barents Sea. The most abundant species are capelin, polar cod and juvenile herring.

Data from the joint Russian-Norwegian ecosystem survey in 2003-2006 showed spatial overlaps with herring, capelin and polar cod at the edge of the blue whiting distribution range (Figure 6), but in general, the distributions of these species were rather distinct. Blue whiting overlapped with capelin and polar cod in the northern and eastern borders of blue whiting distribution in the Barents Sea, as well as along the west coast of Svalbard. Blue whiting and herring overlapped for the most part in the south-western Barents Sea (Figure 6).

We calculated diet similarity between blue whiting and herring, capelin and polar cod. The highest similarity was found for blue whiting and capelin, with the coefficients of diet similarity (CDS) reaching 65-86\% in the Western Deep and on the eastern slope of the Bear Island Bank (Figure 6; Table 4). High diet similarity was mostly due to a high proportion of krill and smaller hyperiids in the diet of both species. The diets of blue whiting and of herring and polar cod were rather different and CDS ranged from 8 to $27 \%$.

\subsection{Blue whiting in diets of predatory fish}


Blue whiting occurred in the stomachs of nine out of 15 predatory fish species analysed (Table 5). Frequency of occurrence was highest in Arctic skate (Amblyraja hyperborea; $6.1 \%$ ), and was $1 \%$ or higher in five other species. Blue whiting contributed most to stomach content in Greenland halibut (Reinhardtius hippoglossoides; 6.8\% by weight), and the contribution exceeded $1 \%$ by weight in six other species. Feeding on blue whiting was spatially concentrated: blue whiting were mainly found in the stomachs of other species along the shelf edge (Figure 7).

Of the potential predators of blue whiting in the Barents Sea, cod is by far the most abundant species. Blue whiting eaten by cod were on average smaller than those caught in the surveys (Figure 4). Blue whiting were only found in $0.6 \%$ of stomachs of cod smaller than $50 \mathrm{~cm}$ (winter and ecosystem surveys 2003-2006), while in larger cod (>50 cm), the percentage of stomachs containing blue whiting varied with season and was $1.5 \%$ in the first quarter and $4 \%$ in the third quarter. In the areas with the highest concentration of blue whiting, blue whiting may make up a large proportion of cod diet (Figure 7).

However, blue whiting and cod have limited spatial overlap: there was no correlation between catches of large $\operatorname{cod}(>50 \mathrm{~cm})$ and blue whiting at station level $(r=-0.05, p=0.1$, $n=4015$, winter and ecosystem surveys pooled). Furthermore, small cod are found in the more shallow eastern parts of the Barents Sea and catches of small cod $(<50 \mathrm{~cm})$ correlated negatively with catches of blue whiting $(\mathrm{r}=-0.2, \mathrm{p}<0.0001, \mathrm{n}=4015)$.

\section{Discussion}

Our work was motivated by the recent dramatic increase in the abundance of blue whiting in the Barents Sea (Heino et al., 2008), although the latest observations (Anon., 2007; 
unpublished data) indicate that the abundance is again declining. The blue whiting has periodically been common in the Barents Sea prior to the recent increase (e.g. in the 1930's: Boldovsky, 1939; Zatsepin and Petrova, 1939). The increased abundance seen from around 2000 seems to be primarily caused by increased numbers of juveniles (ages 14 years) migrating from the Norwegian Sea (Varne and Mork, 2004; Heino et al., 2008). After reaching maturity (2-4 years of age), the majority of these Atlantic blue whiting probably migrated out of the Barents Sea to spawn, and did not return. Therefore, blue whiting are ecologically more similar to Norwegian spring-spawning herring, another highly migratory pelagic fish, than to the resident capelin and polar cod. One consequence of the increased abundance of juvenile blue whiting may then be an increased net transportation of production out of the Barents Sea when they mature. Population genetic studies suggest that there is also a local resident population in the Barents Sea (Giæver and Stien, 1998; Varne and Mork, 2004; Ryan et al., 2005), but this population is and probably always has been relatively small.

Our results suggest that krill are the most important prey of blue whiting in Barents Sea, in agreement with earlier studies (Zilanov 1968, 1982). Krill are the main prey of blue whiting throughout its range: in the Norwegian Sea, in the areas around Iceland, Greenland and Ireland, and on the Porcupine, Rockall and Flemish Cap Banks (Zilanov, 1968, 1982; Dumke, 1981), as well as in the Skagerrak (Degnbol and Munch-Petersen, 1985), in the Norwegian Deep (Bergstad, 1991) and off Portugal (Cabral and Murta, 2002). Zilanov $(1968,1982)$ compared the diets of blue whiting in the Barents and the Norwegian Seas, and found that pelagic hyperiids and krill were equally important for blue whiting in both areas, but that fish were more important in the Barents Sea and the copepod Calanus finmarchicus was more important in the Norwegian Sea. This finding agrees well with our 
results. We found copepods only in $0.05 \%$ of the stomachs, whereas studies from the Norwegian Sea have reported C. finmarchicus in up to $97 \%$ of stomachs (Prokopchuk and Sentyabov, 2006). We also found that blue whiting fed largely on fish, the most important species being polar cod. Blue whiting also included a large proportion of mesopelagic and demersal fish in their diet. The latter is perhaps surprising, given that blue whiting is usually regarded as a mesopelagic species. However, the Barents Sea is a shallow shelf sea, where blue whiting can best be described as benthopelagic. It is known from other areas of the North Atlantic that blue whiting are mainly found at depths beyond 200-300 m (Monstad, 2004), which corresponds to the bottom depths in the areas where blue whiting are found in the Barents Sea.

There are large seasonal differences in blue whiting catch rates, with more being taken in the summer/autumn than the winter in the Barents Sea. This must either reflect seasonal difference in catchability or in abundance of the species (see Methods section). The wider and more even distribution in the second half than the first half of the year suggests that a large proportion of the Barents Sea blue whiting stock is continuous with Norwegian Sea stock, and that the stock contracts and expands into the Barents Sea as part of its seasonal feeding migration, or in response to seasonal changes in the ocean climate. The Barents Sea can therefore be regarded as part of the oceanic blue whiting feeding grounds (Zilanov, 1984). We also found seasonal differences in diets, some of which can be attributed to differences in the spatial survey coverage between the seasons. For instance, we found more fish in diet in the fourth quarter, which was due to the high prevalence of polar cod in blue whiting stomachs along the west coast of Svalbard, an area only covered in this season. This high proportion of empty stomachs in the second quarter might be an artefact of the limited spatial coverage in this quarter. The lowest proportion of empty stomachs 
was in the third quarter. The stomachs also appeared to be full in this quarter, especially along the polar front. This seasonal pattern is also typical in capelin and polar cod in the Barents Sea (Shleinik and Borkin 1986; Orlova et al. 2004). High feeding intensity and the aggregation of predators feeding on zooplankton and pelagic fish along the polar front are well known phenomena in the Barents Sea in summer (e.g. Belopolskii, 1979; Mehlum et al., 1998) and in other areas (e.g. Franks, 1992). Interestingly, the period with the highest proportion of empty stomachs in the Barents Sea (spring) corresponds to the time when blue whiting in the Norwegian Sea feed most intensely on copepods (Monstad, 2004; Prokopchuk and Sentyabov, 2006). There is a seasonal difference in the availability of $C$. finmarchicus between the two areas. The Norwegian Sea is the main spawning area of $C$. finmarchicus, while most of the C. finmarchicus in the Barents Sea are advected into the area (e.g. Dalpadado et al., 2003). Feeding migrations of blue whiting, extending further into the Barents Sea in late summer/autumn and retracting in late winter/spring (above) might be a response to the seasonal dynamics of copepod blooms in the spring in the Norwegian Sea and the high productivity along the front in the Barents Sea in late summer.

In spite of the limited overlap between blue whiting and the other pelagic species in the Barents Sea, food competition from blue whiting may still be important. Krill that are being transported into the Barents Sea from the Norwegian Sea have to pass through the "filter" of blue whiting feeding on krill in the south-western Barents Sea. The amount of krill available to other krill feeders in central and eastern Barents Sea is thereby reduced. Limited krill availability could in turn influence on the energetic condition of pelagic species in the Barents. However, we have no data to support this suggestion. 
Cod is the main predator in the Barents Sea and the only fish predator whose consumption of prey is estimated annually (e.g. ICES, 2007a). However, even though the estimated consumption of blue whiting by cod has increased in proportion to the increase in blue whiting abundance in the Barents Sea, in 2004-2006 blue whiting made up on average only $3 \%$ of the total biomass consumed by cod (B. Bogstad, pers. comm.). In some local areas (especially in the south-western Barents Sea) blue whiting is an important component of cod diet contributing up to $50 \%$ of the diet (by weight) during short peak periods. In general, however, the average contribution of this species to the diet of cod is small due to restricted overlap in distribution of cod and blue whiting, and size dependence in predation limitating predation of blue whiting to only the larger cod. Blue whiting were found in the stomachs of other predatory fish, mainly along the edge of the continental shelf, as previously observed by Zatsepin and Petrova (1939). Blue whiting has been documented in the diet of many species of fish in the Barents Sea in the Russian literature (Zenkevich and Brotskaya, 1931; Komarova, 1939; Zatsepin and Petrova, 1939; Boldovsky, 1944; Antipova and Kovtsova, 1982; Berestovsky, 1989; Antipova and Nikiforova, 1990; Shvagzhdis, 1990; Dolgov 2000). These studies all suggested that in general, blue whiting play a minor role in the diets of various predators, in agreement with the present study. Both our study and all those mentioned above indicate that blue whiting is not a major prey species in the Barents Sea, even when its abundance is very high. Limited spatial overlap between blue whiting and potential predators might be an important explanatory factor. Blue whiting might also be a less preferred prey than certain other species such as herring and capelin. Blue whiting is a lean fish, with a low fat content (2-6 \% in wet tissue, Björnsson, 2001), especially in comparison with herring (10-15\%, Björnsson, 2001) and capelin (8-17 \%, L. Konstantinova, PINRO, unpublished data). Size may also play a role, as the average blue whiting sampled was $24 \mathrm{~cm}$, implying that a cod 
(or similar predator) would have be more than $50 \mathrm{~cm}$ in length to eat it (Bogstad et al., 1994). Cod preyed on blue whiting below the average size found in surveys. We believe that this pattern arises from the constraints that prey size set on predator size, because we are not aware of spatial patterns in blue whiting and cod sizes that could explain it. Indeed, large cod fed on both small and large blue whiting, while smaller cod are restricted to feeding on smaller blue whiting (see also Norvillo, 1989). Thus, the predation pressure on blue whiting of average size or larger appears to be relatively low.

\section{Conclusions}

Krill are the most important prey of blue whiting in the Barents Sea. Our results agree well with findings on blue whiting diet in the Barents Sea in the 1960s and 70s, and corroborate these findings when it comes to the difference in blue whiting diet in the Norwegian and Barents Sea, with less copepods and more fish in the diet in the Barents Sea. However, the ecological significance of blue whiting seems to be moderate in the Barents Sea. The growing abundance of blue whiting in the Barents Sea is probably due to an increase in the northern component of the oceanic stock, which migrates out of the Barents Sea to spawn west of the British Isles, probably never to return. There is limited predation on blue whiting in the Barents Sea. Our results thus suggest a scenario in which the increased abundance of blue whiting of Atlantic origin channels more of the production in the Barents away from that ecosystem, with less production being channelled further up the food chain.

\section{Acknowledgements}

We thank all who carried out the stomach content analysis. We thank two anonymous reviewers for their helpful comments and Hugh M. Allen for correcting of the English. MH 
acknowledges the funding from Bergen Research Foundation. EJ acknowledge financial support from NFR project 173348/S40. 


\section{References}

Anon 2004. Survey report from the Joint Norwegian/Russian ecosystem survey in the Barents Sea August-October 2004 (vol. 1). IMR/PINRO Joint Report Series, No. 3/2004. ISSN 1502-8828. $68 \mathrm{pp}$.

Anon 2005. Survey report from the Joint Norwegian/Russian ecosystem survey in the Barents Sea August-October 2005 (vol. 1). IMR/PINRO Joint Report Series, No. 3/2005. ISSN 1502-8828. 99 pp.

Anon 2006a. Survey report from the Joint Norwegian/Russian ecosystem survey in the Barents Sea August-October 2006 (vol. 1). IMR/PINRO Joint Report Series, No. 2/2006. ISSN 1502-8828. 90 pp.

Anon. 2006b. Methodic manual on instrumental surveys of the commercial hydrobionts stocks in areas of PINRO studied. Murmansk, PINRO Press. 163 pp. (in Russian)

Anon. 2007. Survey report from the Joint Norwegian/Russian ecosystem survey in the Barents Sea August-October 2007 (vol. 1). IMR/PINRO Joint Report Series, No. 4/2007. ISSN 1502-8828. $97 \mathrm{pp}$.

Antipova, T. V., and Kovtsova, M. V. 1982. Daily, seasonal and annual changes of feeding and condition of the Barents Sea plaice. In Ecology and fisheries of demersal fish of the North European basin, pp. 43-56. PINRO Press, Murmansk. 127 pp. (in Russian) 
Antipova, T. V., and Nikiforova, T. B. 1990. Peculiarities of feeding of thorny skate in the Barents Sea. In Food resources and trophic relationships of fish in North Atlantic, pp.167172. PINRO Press, Murmansk. 228 pp. (in Russian)

Bailey, R. 1982. The population biology of blue whiting. Advances in Marine Biology, 19: 257-355.

Belikov, S. V., Sokolov, A. M., and Dolgov, A. V. 2004. Blue whiting. In Investigations by PINRO in the Spitsbergen Archipelago area, pp. 167-177. Ed. by M. S. Shevelev. Murmansk, PINRO Press. 414 pp. (in Russian)

Belopolskii, L. O. 1979. Analysis of factors determining mass concentrations of seabirds on the open ocean, along the shores, and on ocean islands. Doklady Akademii Nauk SSSR, 249(5): 1266-1269. (In Russian).

Berestovsky, E. G. 1989. Feeding of skates Raja radiata and Raja fyllae in the Barents Sea. Voprosy ikhtiologii, 29(6): 994-1002. (in Russian)

Bergstad, O. A. 1991. Distribution and trophic ecology of some gadoid fish of the Norwegian Deep. 2. Food-web linkages and comparison of diets and distributions. Sarsia, 75: $315-325$.

Björnsson, B. 2001. Can fisheries yield be enhanced by large-scale feeding of a predatory fish stock? A case study of the Icelandic cod stock. Canadian Journal of Fisheries and Aquatic Sciences, 58: 2091-2104. 
Bogstad, B., Haug, T., and Mehl, S. 2000. Who eats whom in the Barents Sea? NAMMCO Scientific Publications, 2: 98-119.

Bogstad, B., Lilly, G. R., Mehl, S., Palsson, O. K., and Stefansson, G. 1994. Cannibalism and year-class strength in Atlantic cod (Gadus morhua L.) in Arcto-boreal ecosystems (Barents Sea, Iceland, and eastern Newfoundland). ICES Marine Science Symposia, 198: 576-599.

Boldovsky, G. V. 1939. Warmwater gadoids in the Barents Sea. Reports of the USSR Academy of Science, 24(2): 307-309. (in Russian)

Boldovsky, G. V. 1944. Feeding of the Barents Sea redfish. Trudy PINRO, 8:307-330. (in Russian)

Cabral, H. N., and Murta, A. G. 2002. The diet of blue whiting, hake, horse mackerel and mackerel off Portugal. Journal of Applied Ichthyology, 18: 14-23.

Dalpadado, P., Ingvaldsen, R., and Hassel, A. 2003. Zooplankton biomass variation in relation to climatic conditions in the Barents Sea. Polar Biology, 26: 233-24.

Degnbol, P., and Munch-Petersen, S. 1985. On the relation between diurnal migration and feeding of Blue whiting in the Skagerrak. ICES Document CM 1985/H: 46. 15 pp. 
Dolgov, A. V. 2000. Feeding and food consumption by the Barents Sea predatory fishes in the 1980-90s. ICES Document CM 2000/Q: 02. 17 pp.

Dumke, A. 1983. Feeding investigations of Blue whiting (Micromesistius poutassou) in the Norwegian Sea. ICES CM 1983/H:58, 9 pp.

Du Buit, M. H. 1995. Blue whiting in food webs in the Celtic Sea. Journal of Fish Biology, 45A: 245.

Franks, P. J. S. 1992. Sink or swim: accumulation of biomass at fronts. Marine Ecology Progress Series, 82: 1-12.

Giæver, M., and Stien, J. 1998. Population genetic substructure in blue whiting based on allozyme data. Journal of Fish Biology, 52: 782-795.

Hamre, J. 1994. Biodiversity and exploitation of the main fish stocks in the NorwegianBarents Sea ecosystem. Biodiversity and Conservation, 6: 473-492.

Heino, M., Engelhard, G. H., and Godø, O. R. 2008. Ocean climate and migrations determine the abundance fluctuations of blue whiting in the Barents Sea. Fisheries Oceanography, 17: 153-163.

ICES. 2007a. Report of the Northern Pelagic and Blue Whiting Fisheries Working Group. ICES Document CM 2007/ACFM: 29. 229 pp. 
ICES. 2007b. Report of the Arctic Fisheries Working Group. ICES Document CM 2007/ACFM: 16. 641 pp.

Jakobsen, T., Korsbrekke, K., Mehl, S., and Nakken, O. 1997. Norwegian combined acoustic and bottom trawl surveys for demersal fish in the Barents Sea during winter. ICES Document CM 1997/Y: 17. 8 pp.

Komarova, I. V. 1939. Feeding of long rough dab (Hippoglossoides platessoides) in the Barents Sea related to food resources. Trudy VNIRO, 4: 297-320. (in Russian).

Lepesevich, Yu. M., and Shevelev, M. S. 1997. Evolution of the Russian survey for demersal fish: from ideal to reality. ICES Document CM 1997/Y:09.

Mehl, S., and Yaragina, N. A. 1992. Methods and results in the joint PINRO-IMR stomach sampling program. In Interrelations between fish populations in the Barents Sea. Proceedings of the Fifth PINRO-IMR Symposium, 12-16 August 1991, Murmansk, pp. 516. Ed. by B. Bogstad, and S. Tjelmeland. Institute of Marine Research, Bergen, 238 pp.

Mehlum, F., Nordlund, N., and Isaksen, K. 1998. The importance of the "Polar Front" as a foraging habitat for guillemots Uria spp. breeding at Bjørnøya, Barents Sea. Journal of Marine Systems, 14: 27-43.

Monstad, T. 2004. Blue Whiting. In The Norwegian Sea Ecosystem, pp. 263-288. Ed. by H. R. Skjoldal. Tapir Academic Press, Trondheim. 559 pp. 
Norvillo, G. V. 1989. New objects in the food ration of Arcto-Norwegian cod. In Trophic relationships of benthos organisms and demersal fish of the Barents Sea, pp. 42-44. Kola Science Center of Russian Academy of Science Press, Apatity. 119 pp. (in Russian)

Orlova, E. L., and Matishov, G. G. 1993. Structural and functional role of cod in the Barents Sea ecosystem. Kola Science Center of Russian Academy of Science Press, Apatity, 166 pp. (in Russian)

Orlova E.L., Boitsov V.D., Ushakov N.G. 2004. Conditions of summer feeding and growth of the Barents Sea capelin. PINRO Press, Murmansk.198 pp. (in Russian)

Prokopchuk, I., and Sentyabov, E. 2006. Diets of herring, mackerel, and blue whiting in the Norwegian Sea in relation to Calanus finmarchicus distribution and temperature conditions. ICES Journal of Marine Science, 63: 117-127.

Ryan, A. W., Mattiangeli, V., and Mork, J. 2005. Genetic differentiation of blue whiting (Micromesistius poutassou Risso) populations at the extremes of the species range and the Hebrides-Porcupine Bank spawning grounds. ICES Journal of Marine Science, 62: 948955.

Shleinik B.N., Borkin I.V. 1986. Polar cod. In: Ichthyofauna and its habitat conditions in the Barents Sea. Apatity, Kola center of Academy of Science of USSR. P.12-16. (in Russian). 
Shorygin, V. A. 1952. Feeding and trophic relations of fishes of the Caspian Sea. Pistchepromizdat, Moscow. 325 pp. (in Russian)

Shvagzhdis, A. P. 1990. Feeding peculiarities of Greenland halibut from the NorwegianBarents Sea stock in1980-1989. ICES Document CM 1990/G: 12. 19 pp.

Skjoldal, H. R. (Ed.) 2004. The Norwegian Sea Ecosystem. Tapir Academic Press, Trondheim. 559 pp.

Timokhina, A. F. 1974. Feeding and daily food consumption of the blue whiting (Micromesistius poutassou) in the Norwegian Sea. Journal of Ichthyology, 14: 760-765.

Varne, R., and Mork, J. 2004. Blue whiting (Micromesistius poutassou) stock components in samples from the northern Norwegian Sea and Barents Sea, winter 2002. ICES Document CM 2004/EE: 16.9 pp.

Yaragina, N. A., and Dolgov, A.V. 2009. Ecosystem structure and resilience- a comparison between the Norwegian and the Barents Sea. Deep Sea Research (in press).

Zatsepin, V. J., and Petrova, N. S. 1939. The feeding of the cod in the south part of the Barents Sea (by observations in 1934-1938). Trudy PINRO, 5. 170 pp. (in Russian).

Zenkevich, L. A., and Brotskaya, V. A. 1931. Data on feeding of fishes from the Barents Sea. Reports of the first session of the State Oceanographic Institute, 4: 1-35. (in Russian). 
Zilanov, V. K. 1968. Some data on the biology of Micromesistius poutassou (Risso) in the North-east Atlantic. Rapports et Procès-Verbaux des Réunions du Conseil International pour l'Exploration de la Mer, 157: 116-122.

Zilanov, V. K. 1982. Data on feeding and fatness of blue whiting. ICES Document CM 1982/H:12.

Zilanov, V. K. 1984. Blue whiting of North Atlantic. Legkaya i pitchevaya promyshlennost Publishing, Moscow, 160 pp. (in Russian) 